\title{
Anal pressure studies in spinal patients
}

\author{
I. C. WHEATLEY, K. J. HARDY, AND J. DENT \\ From the University of Melbourne, Department of Surgery, Repatriation General and Austin Hospital, \\ Melbourne, Australia
}

SUMMARY Maximal anal sphincter pressure was measured in 22 patients with spinal cord lesions and in a group of 10 controls, using perfused sleeve manometry. The mean resting pressure of the spinal patients was $63 \pm 8(\mathrm{SEM}) \mathrm{mm} \mathrm{Hg}$, and of the control group $116 \pm 14(\mathrm{SEM}) \mathrm{mm} \mathrm{Hg}$, $\mathbf{P}<0.01$. When the rectum was distended by a balloon inflated with $100 \mathrm{ml}$ of air a fall in anal sphincter pressure to $33 \pm 6(\mathrm{SEM}) \mathrm{mm} \mathrm{Hg}$ in the spinal group and to $78 \pm 10$ (SEM) $\mathrm{mm} \mathrm{Hg}$ in the control group was observed.

The anal sphincter pressure (ASP) of paraplegic patients has been measured in small groups using air or water-filled balloon tipped catheters (Gowers, 1877; Denny-Brown and Robertson, 1935; Schuster et al., 1963; Ala et al., 1965; Ihre, 1974; Frenckner, 1975). Such measurements vary with the mechanical properties of the balloon, and the resistance of the sphincter to the presence of the balloon. Pressures recorded with non-perfused water-filled catheters are inaccurate (Winans and Harris, 1967). With the use of constantly perfused catheters with sideholes, displacement of the sidehole out of the narrow zone of maximal activity where the pressure is being recorded creates a considerable problem in localising the site of pressure measurement. A pressure sensor which accurately measures maximal pressure along its length has been developed and validated by Dent (1976). The aim of this study was to measure maximal ASP in absolute units in patients with spinal cord lesions and in a control group of hospital patients using the new technique.

\section{Methods}

Anal pressures were measured in 22 spinal patients requiring long-term hospital treatment at the Victorian Spinal Injuries Unit at the Austin Hospital, Australia. The spinal injuries ranged from the spinal cord level of fifth cervical to 10th thoracic vertebra. Ten patients without bowel or anorectal symptoms, admitted to hospital for a wide range of diagnoses, served as the control group.

Received for publication 19 November 1976

\section{APPARATUS}

The sensor is a $6 \mathrm{~cm}$ long sleeve of thin silicon rubber with a $4 \mathrm{~mm}$ lumen, shown in cross-section in Figs. 1 and 2. This sensor is bonded to one side of a twin lumen catheter assembly and a third tube, $1.57 \mathrm{~mm}$ internal diameter, is glued into the proximal sleeve end, while the distal end of the sleeve is left open. One of the twin tubes is connected to a balloon $10 \mathrm{~cm}$ beyond the distal sleeve end. The greatest diameter of the sensor is $7 \mathrm{~mm}$. The sleeve is perfused with water at $109 \mathrm{ml} / \mathrm{h}$ and sphincter activity modulates cuff resistance to water flow. This relatively high flow rate does not alter the absolute pressure recorded but improves the dynamic performance of the sleeve. The resultant perfusion line pressure, measured by a conventional external transducer, reflects maximal sphincter pressure (Dent, 1976). The recorder was a Mingograf 34, the transducer an Elema Schonander type EMT 34, and the perfusion was via a Braun syringe pump.

\section{TECHNIQUE}

Catheter perfusion was started before the insertion of the pressure sensor into the anal canal, and a baseline pressure taken at the level of the midnatal cleft with the patient in the left lateral position. The lubricated catheter was then inserted and the perfused sleeve positioned in the anal canal with the deflated balloon $10 \mathrm{~cm}$ away from the anal verge. The basal ASP and its subsequent response to balloon inflation with $100 \mathrm{ml}$ of air were measured in both study and control groups of patients. Statistical analysis was performed using Student's $t$ test for paired and unpaired values where appropriate. 

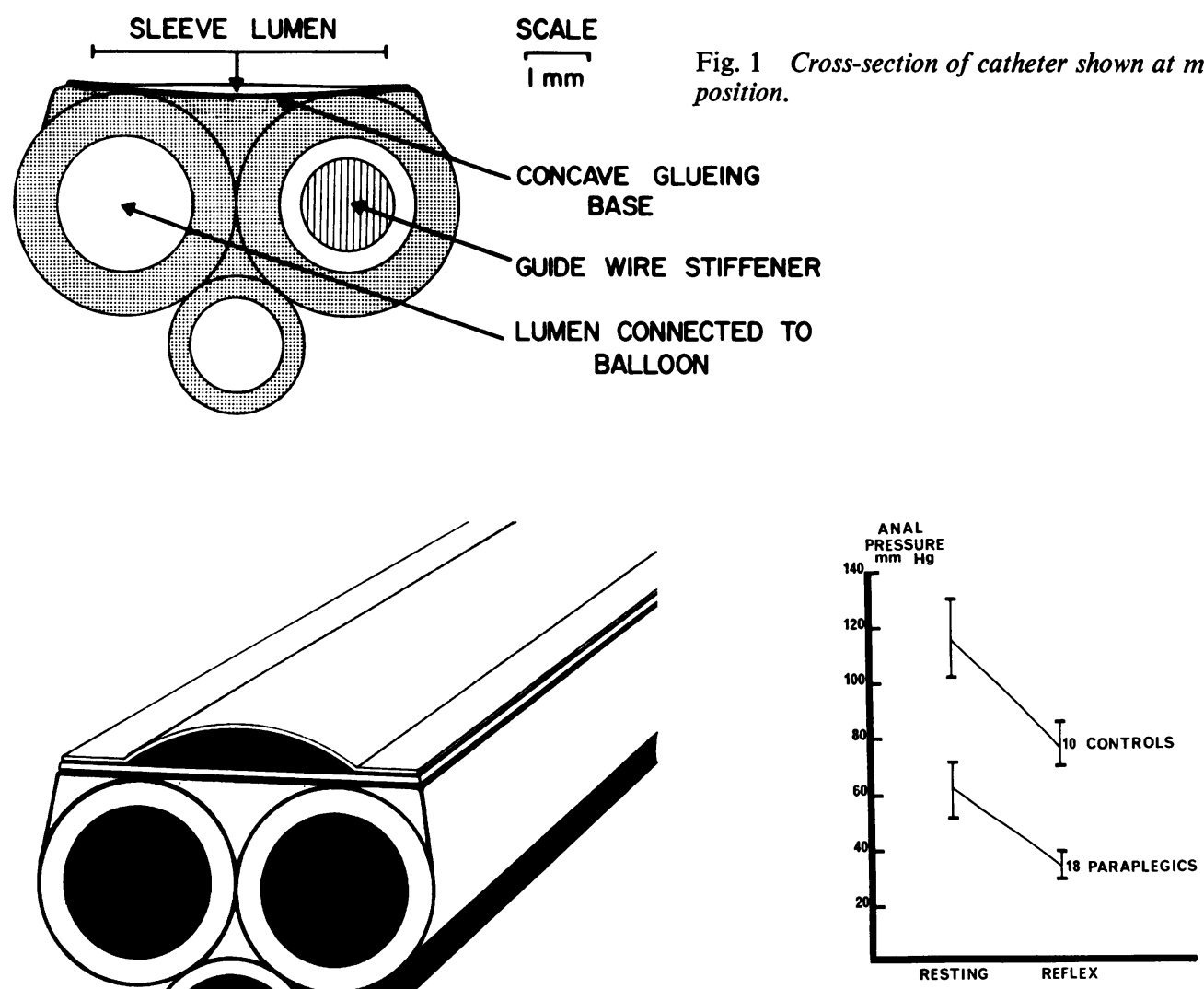

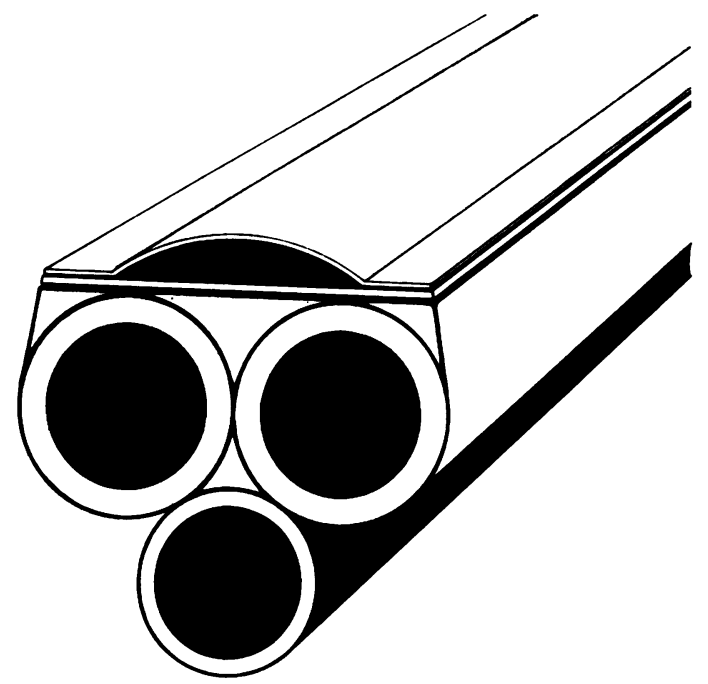

Fig. 2 An oblique view of a cross-section of the sleeve to show the sleeve on top of the tube assembly.

\section{Results}

Of the 22 spinal patients studied, four were excluded from analysis as they defaecated with inflation of the balloon in the rectum. The mean resting pressure of the remaining spinal patients was $63 \pm 8$ (SEM) $\mathrm{mm} \mathrm{Hg}$. The mean resting ASP of the control group was $116 \pm 14$ (SEM) $\mathrm{mm} \mathrm{Hg}$ (Fig. 3). This difference was significant $(\mathrm{P}<0.01)$. Two spinal patients had an ASP greater than $100 \mathrm{~mm} \mathrm{Hg}$ : both of these had lesions at the sixth cervical level and they were the only patients with incomplete interruption of spinal pathways.

Rectal distension by the balloon did not produce a sensation of fullness in any spinal patient. Rectal fullness was felt by all of the control group. The anorectal reflex of both groups showed a significant drop in pressure. ASP in the spinal group fell from $63 \pm 8$ (SEM) $\mathrm{mm} \mathrm{Hg}$ to $33 \pm 6$ (SEM); the comparison group fell from $116 \pm 14$ (SEM) to $78 \pm 10$ (SEM) maintaining an approximate $50 \mathrm{~mm}$ $\mathrm{Hg}$ difference between the groups (Fig. 3) (P < 0.01).

\section{Discussion}

The focal pressure sampling zone of a constantly perfused side hole catheter allows easy displacement from the narrow region of maximal pressure in the lower oesophageal sphincter (Dodds et al., 1974). The anal sphincter has a peaked pressure profile (Hill et al., 1960; Gutierrez et al., 1975) so that very accurate positioning of a side hole catheter is needed for measurement of maximal ASP. With the perfused sleeve system used in our study, the region of maximal pressure can move along the length of the sleeve 
without significant change in the pressure registered. This property of the sensor removes the need for critical catheter positioning and ensures continuous recording of maximal ASP during reflex responses likely to cause significant displacement of a side hole catheter. Measurement of ASP in normal subjects by either balloon or non-perfused catheter techniques gives lower pressures than the pressures recorded in our study (Hancock and Williams, 1973; Collins et al., 1967; Frenckner, 1975). However, when ASP is measured by a pull-through method with a constantly perfused side hole catheter of similar dimensions to our study, similar pressures are recorded: $117 \pm 5$ (SEM $\mathrm{mm} \mathrm{Hg}$, (Gutierrez et al., 1975) compared with $116 \pm 14$ (SEM) $\mathrm{mm} \mathrm{Hg}$ of our controls.

Palpatation of the anal sphincter of patients with paraplegia suggests that basal ASP is reduced. Absolute pressure measurements, reported here, indicate that patients with paraplegia have a low basal ASP. Frenckner (1975), in a study of eight paraplegic patients and eight controls, found a lower basal ASP in the paraplegic group compared with the control group using a balloon technique, though in the small group studied this did not reach statistical significance.

Basal tone of the anal sphincter is considered to be a mainly internal sphincter activity, and this activity is a continuing safety mechanism preventing minor leaks of faeces, flatus, or mucus. The exact origin of anal sphincter tone is uncertain, but this tone appears to persist after interruption of spinal nervous connections (Frenckner, 1975). The external anal sphincter exhibits tonic activity, and in conditions of sphincter stress it contracts powerfully in conjunction with the puborectalis. Low ASP in paraplegia is suggested from diminished tonic external activity. Electromyographic studies of this component in a limited number of paraplegic patients have produced conflicting results with reports of diminished (Ala et al., 1965), normal (Parks et al., 1962), and increased activity (Abramson et al., 1966). Thus it appears that in some situations external anal sphincter tone can originate solely from lower spinal centres.

Rectal distension is followed by immediate anal sphincter relaxation which is independent of spinal nervous connections (Duthie and Bennett, 1963). This response, known as the anorectal reflex, is ascribed to internal anal sphincter relaxation via intramural nervous pathways. Other studies (Denny Brown et al., 1935; Schuster et al., 1963), have reported preservation of the reflex in paraplegic patients.

Further studies are required to measure the sphincter response to interruption of the extraspinal nervous pathways.

Acknowledgement is given to Dr D. Burke and staff of the Spinal Injuries Unit, Austin Hospital, for their assistance in performing this study. J. Dent acknowledges support from the Australian National Health and Medical Research Council as a Postgraduate Medical Scholar.

\section{References}

Abramson, A. S., Roussan, M. S., and D'Oronzio, G. (1966). Method for evaluating function of the neurogenic bladder. Journal of the American Medical Association, 195, 554-558.

Ala, J., Mendeloff, A. I., Hendrix, T. R., and Schuster, M. M. (1965). Studies of fecal incontinence by combined manometric-electromyographic techniques. Gastroenterology, 48, 863.

Collins, C. D., Duthie, H. L., Shelley, T., and Whittaker, G. E. (1967). Force in the anal canal and anal continence. Gut, 8, 354-360.

Denny-Brown, D., and Robertson, G. (1935). An investigation of the nervous control of defaecation. Brain, 58, 256-310.

Dent, J. (1976). A new technique for continuous sphincter pressure measurement. Gastroenterology, 71, 263-267.

Dodds, W. J., Stewart, E. T., Hogan, W. J., Stef, J. J., and Arndorfer, R. C. (1974). Effect of esophageal movement on intraluminal esophageal pressure recording. Gastroenterology, 67, 592-600.

Duthie, H. L., and Bennett, R. C. (1963). The relation of sensation in the anal canal to the functional anal sphincter: a possible factor in anal continence. Gut, 4, 179-182.

Frenckner, B. (1975). Function of the anal sphincters in spinal man. Gut, 16, 638-644.

Frenckner, B., and V. Euler, C. (1975). Influence of pudendal block on the function of the anal sphincters. Gut, 16. 482-489.

Gowers, W. R. (1877). The automatic action of the sphincter ani. Proceedings of the Royal Society B., 26, 77-84.

Gutierrez, J. G., Oliai, A., and Chey, W. Y. (1975). Manometric profile of the internal anal sphincter in man. Gastroenterology, 68, A-50 907.

Hancock, B., and Williams, P. (1973). Anal pressure profiles before and after anorectal dilatation for haemorrhoids. (Abstr.) European Surgical Research, 5, suppl. 2., 20.

Hill, J. R., Kelley, M. L., Schlegel, J. F., and Code, C. F. (1960). Pressure profile of the rectum and anus of healthy persons. Diseases of the Colon and Rectum, 3, 203-209.

Ihre, Thomas (1974). Studies on anal function in continent and incontinent patients. Scandinavian Journal of Gastroenterology, 9, suppl 25.

Parks, A. G., Porter, N. H., and Melzak, J. (1962). Experimental study of the reflex mechanism controlling the muscles of the pelvic floor. Diseases of the Colon and Rectum, 5, 407-414.

Schuster, M. M., Hendrix, T. R., and Mendeloff, A. I. (1963). The internal anal sphincter response: manometric studies on its normal physiology, neura pathways, and alteration in bowel disorders. Journal of Clinical Investigation, 42, 196-207.

Winans, C. S., and Harris, L. D. (1967). Quantitation of lower esophageal sphincter competence. Gastroenterology, 52, 773-778. 